\title{
(2) \\ OPEN ACCESS \\ A patient-initiated voluntary online survey of adverse medical events: the perspective of 696 injured patients and families
}

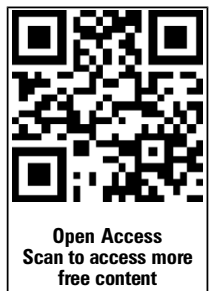

- Additional material is published online only. To view please visit the journal online (http://dx.doi.org/10.1136/bmjqs2015-003980)

${ }^{1}$ Department of Medicine, University of Florida, Gainesville, Florida, USA

${ }^{2}$ Department of Behavioral Science and Community Health, College of Public Health and Health Professionals, University of Florida, Gainesville, Florida, USA

${ }^{3}$ Empowered Patient Coalition, San Francisco, California, USA

\section{Correspondence to} Dr Frederick S Southwick, Department of Medicine, University of Florida, 1600 Archer Rd, Box 100277, Gainesville, FL 32610, USA; southf@epi.ufl.edu

Received 19 January 2015 Revised 20 May 2015 Accepted 30 May 2015 Published Online First 19 June 2015

\section{CLinked}

- http://dx.doi.org/10.1136/ bmjqs-2015-004573 CrossMark

To cite: Southwick FS, Cranley NM, Hallisy JA. BMJ Qual Saf 2015;24:620-629.

\author{
Frederick S Southwick, ${ }^{1}$ Nicole M Cranley, ${ }^{2}$ Julia A Hallisy ${ }^{3}$
}

\begin{abstract}
Background Preventable medical errors continue to be a major cause of death in the USA and throughout the world. Many patients have written about their experiences on websites and in published books.

Methods As patients and family members who have experienced medical harm, we have created a nationwide voluntary survey in order to more broadly and systematically capture the perspective of patients and patient families experiencing adverse medical events and have used quantitative and qualitative analysis to summarise the responses of 696 patients and their families.
\end{abstract}

Results Harm was most commonly associated with diagnostic and therapeutic errors, followed by surgical or procedural complications, hospitalassociated infections and medication errors, and our quantitative results match those of previous provider-initiated patient surveys. Qualitative analysis of 450 narratives revealed a lack of perceived provider and system accountability, deficient and disrespectful communication and a failure of providers to listen as major themes. The consequences of adverse events included death, post-traumatic stress, financial hardship and permanent disability. These conditions and consequences led to a loss of patients' trust in both the health system and providers. Patients and family members offered suggestions for preventing future adverse events and emphasised the importance of shared decision-making. Conclusions This large voluntary survey of medical harm highlights the potential efficacy of patient-initiated surveys for providing meaningful feedback and for guiding improvements in patient care.

Despite the efforts of many dedicated professionals, modern healthcare continues to endanger the lives and well- being of many patients. The incidence of avoidable medical harm remains high in healthcare settings. ${ }^{1}$ The consequences of medical harm are profound, and many patients and family members have described their personal stories on websites $^{2-10}$ and in books. ${ }^{11-20}$ Previous work comparing patient reports of medical errors to hospital records reveal that patients are able to accurately identify preventable adverse events, and many of the events they report are not captured by the hospital incident reporting system or recorded in the medical record. ${ }^{21-23}$

Systematic patient-initiated data collection on medical errors is rare. As patients $^{24}$ and family members ${ }^{25} 26$ of patients who have been harmed by preventable adverse events, we wanted to more broadly and systematically capture the patient perspective on the issues surrounding adverse medical and surgical events, as well as document the perceived impact these events have on patients and their families. To this end we created and administered a voluntary online survey (see online supplementary file).

\section{METHODS}

Survey

This voluntary survey was posted on the Empowered Patient Coalition (EPC) website (see online supplementary file) and was administered from January 2010 to November of 2013 using a password secure version of Survey Monkey that included both quantitative and openended qualitative question formats. EPC volunteers created the quantitative survey based on the categorisation of adverse medical errors by the Office of Inspector General (OIG) in their March 2010 
report. ${ }^{27}$ Additional questions were added to assess the personal impact of adverse events on patients and their families. These questions were based on the EPC volunteers' personal experiences and those of fellow patients and families. The survey is available online https://www.surveymonkey.com/r/?sm = p7JEPTM4TYa \%2bxOAO1GILMQ\%3d\%3d

\section{Participants}

Participants were first recruited via email using the email contact list of the Safe Patient Project, a Consumers Union sponsored organisation that recruits patients and patient advocates to work to improve the safety of medical care. Subsequently recruits were obtained through the EPC website, an organisation founded in 2009 as a consumer and advocate-led effort to inform, engage and empower the public to assume a greater role in their own medical treatment, and to become a driving force for meaningful healthcare reform. The coalition is a 501(c) charitable organisation. ${ }^{26}$

Respondents were predominantly from the USA (681/696) and from every state except North Dakota. The number of respondents closely correlated with each states population $(r=0.966$, figure 1A) and encompassed patients ranging from age 2 to 90 years (mean age 54.9 $\pm 20 \mathrm{SD}$ ) (figure $1 \mathrm{~B}$ ). Of those who filled in the male/female category, more females reported adverse events $(n=394)$ than males (279). Patients (346) and relatives (332) primarily filled out the surveys, the remaining respondents being friends (10), healthcare professionals (6), a patient advocate and a pastor. The majority of reported events occurred within the 5-year intervals of 2001-2005 $(n=169)$ and 2006-2010 $(n=307)$, but extended from 1972 to 2013 (figure 1C).
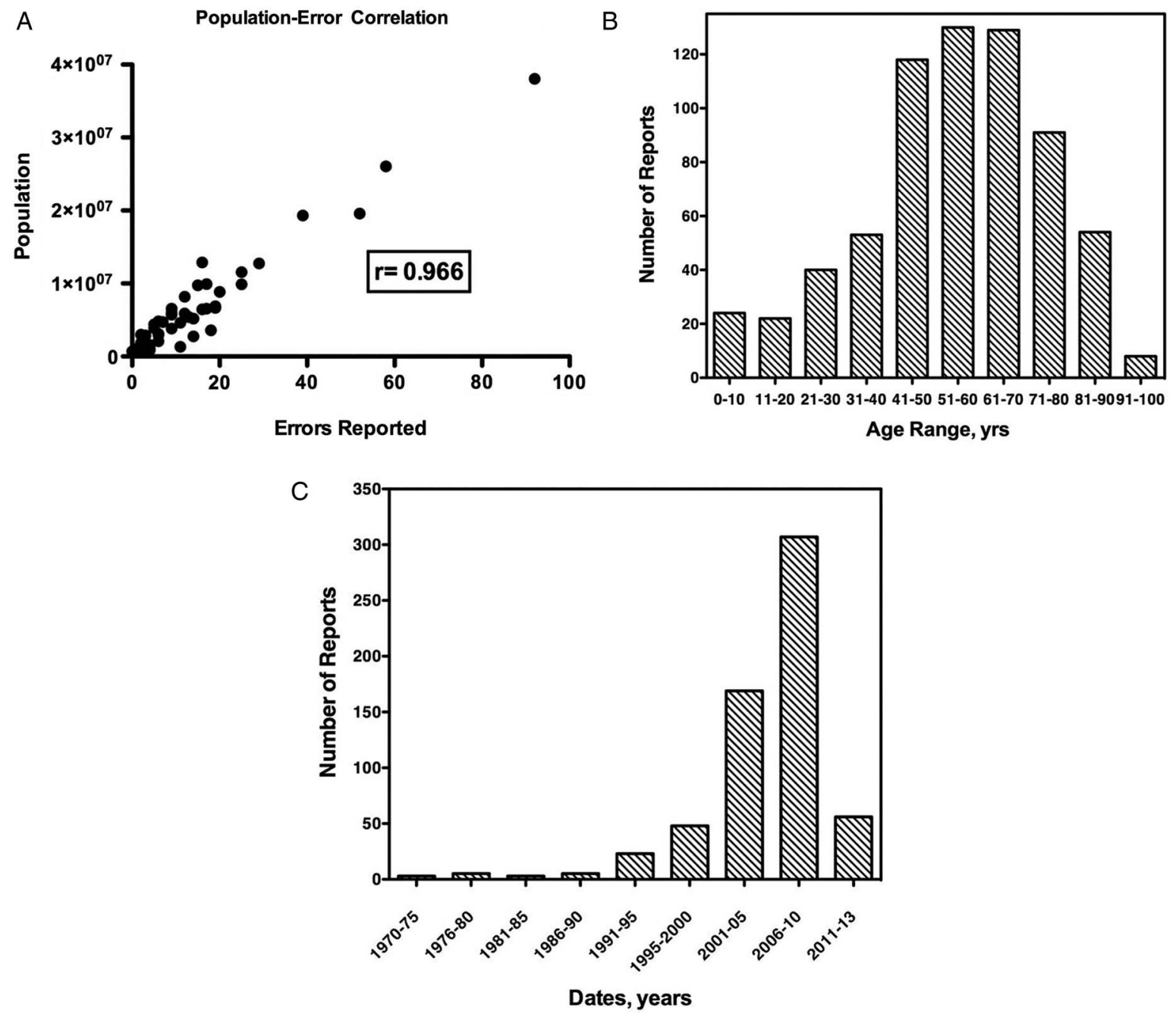

Figure 1 (A) Plot of state population versus number of errors reported per state. With one exception, North Dakota (one of the three least populated states), reports originated from every state in the USA, and the number of error reports closely correlated with the population of each state $(r=0.966)$ (see table 1). (B) Bar graphs showing the age distribution of harmed patients. The ages of harmed patients ranged from under 2 to over 90 years with the peak number of cases being seen in the age ranges of 41-50 years (118), 51-60 years (130) and 61-70 years (129). (C) Bar graphs showing the distribution of reported cases over 5-year intervals. The dates ranged from 1972 to 2013, with the majority of cases being reported within the 5-year intervals of 2001-2005 ( $n=169$ ) and 2006-2010 (n=307). 
Table 1 Categorisation and distribution of adverse medical events

\begin{tabular}{lll}
\hline Category & Per cent & Number \\
\hline Failure of diagnosis or treatment & 30.0 & 541 \\
Surgical-related or procedure-related complications & 24.5 & 442 \\
Healthcare-associated infections & 22.5 & 406 \\
Adverse medication event & 17.7 & 320 \\
Miscellaneous & 5.3 & 96 \\
Total & 100 & 1805 \\
\hline
\end{tabular}

Percentages were calculated using the total number of events as the denominator.

\section{Measurement}

The quantitative section of the survey allowed respondents to place their perceived adverse events into specific categories as defined by previous surveys. ${ }^{27}$ Examples of quantitative survey questions are shown here:

\section{Check all that apply:}

1. adverse surgical procedures-unintentional cut, puncture or tear

2. infections-pneumonia, urinary tract infection, sepsis

3. adverse medication events-overdose, given medication that was not prescribed for him/her or was intended for another patient, medication prescribed to which the patient was known to be allergic.

Questions regarding infections were included in both the section related to 'surgical-related or procedure-related errors' and 'hospital-associated infections' to assure that respondents were given every opportunity to be as specific as possible in identifying and classifying healthcare-associated infections.

Respondents were also given the opportunity to provide a written narrative regarding the incident and any additional comments or suggestions for how the incident might have been prevented. This question provided participants an opportunity to share their experiences and make suggestions for improvement. All narratives were thoroughly screened for any identifying information prior to analysis.

The narrative transcripts were read and reviewed by all three authors. One author (NMC) performed the coding, applying open coding methods to identify emergent themes and creating a codebook that was repeatedly discussed among the authors. The narratives were closely read and coded line by line. All authors used 'memoing' techniques to create an ongoing audit trail to document study findings and to track methodological and substantive decisions made during the analysis. ${ }^{28}$ The memos served to record the thought process during coding and analysis. The authors met regularly to discuss emerging themes and ideas. Any differences of opinion regarding the meaning of respondent narrative was discussed and resolved among the authors and additional outsider reviewers. All coding was conducted in QSR International's NVivo 10 qualitative data management software. ${ }^{29}$ As more narratives were analysed, codes were grouped into new and refined thematic categories by applying constant comparative analysis. ${ }^{30}$ This process continued until saturation had been reached. $^{28} 30$

\section{RESULTS}

There were 696 participants who filled out the quantitative survey. Four hundred and fifty participants also provided written narratives that ranged from just a few words to several pages. Nearly half of the narratives were from patients and the remainder primarily from family members. The majority of family narratives indicated that their family member had died.

Our results begin with the quantitative findings followed by descriptions of the major themes identified in our qualitative analysis of open narratives. Each theme is accompanied by representative quotes.

\section{Adverse event categories and relative frequency}

As shown in table 1 , the leading category of error reported by patients was failure in diagnosis and treatment. Further breakdown of this category revealed the leading event (subcategory) was a delay in diagnosis and treatment. Misdiagnosis was another frequent event, as was failure to rescue a patient whose clinical condition was worsening. The second most common category was surgical or procedural complications. Wrong site surgery was surprisingly common in our survey $(4.3 \%)$, as were foreign objects left in the patient (3.6\%). Hospital-associated infections were the third most common category, sepsis being the most frequently reported complication, followed by postoperative infections, Clostridium difficile intestinal infection and urinary tract infections. Medication errors were the fourth major category in our survey. It is of interest that a significant percentage $(12.8 \%)$ reported receiving medications that they were known to have had an allergic reaction to in the past.

\section{Deficient provider and system accountability}

A high percentage of responses $(90 \%)$ in the quantitative survey expressed concern over a lack of provider accountability. Patients and families indicated a belief that their health systems and providers often failed to respond appropriately to their suffering. As outlined in figure $2 \mathrm{~A}$, the responses included insistence by the provider that the care had been appropriate despite the family's assessment to the contrary $(48 \%)$, denial of responsibility (47\%), a secretive approach combined with an unwillingness to include the family in the investigation (40\%). One-third of respondents reported that the healthcare providers who initially 


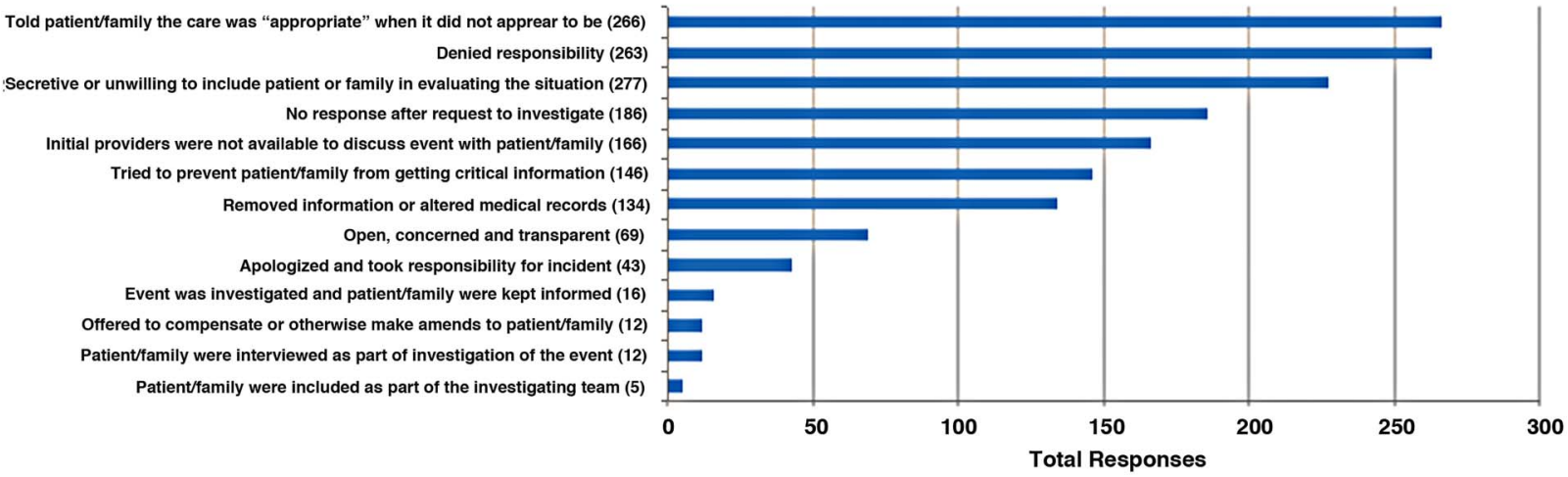

B

\section{Patient Outcome from Event} (648 resondents/1771 events)

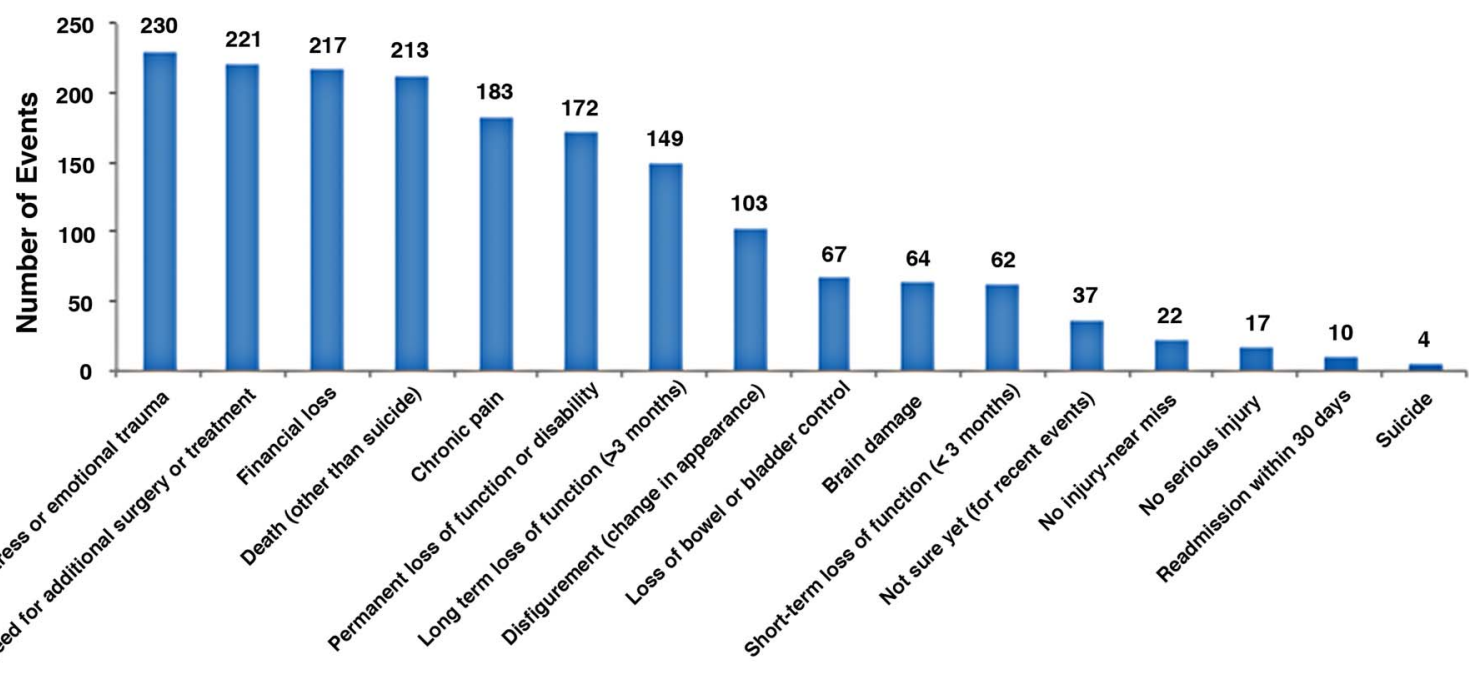

C

Effect of Adverse Event on Patient's Family (605 respondents/1851 responses)

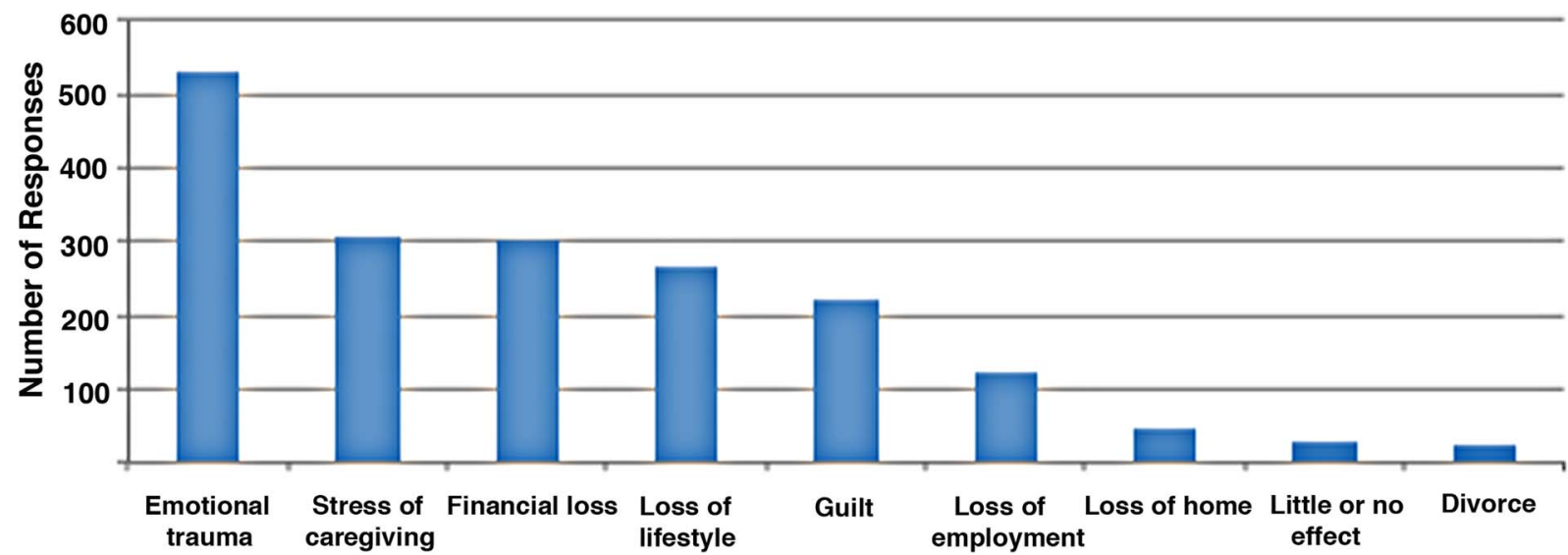

Figure 2 Bar graphs showing patient and family assessment of the impact of and responses by healthcare systems to adverse events. (A) Responses of the healthcare systems; (B) patient impact; (C) family impact. 
cared for them refused further communication following the adverse event. These quantitative findings were bolstered by patient and family narratives expressing a sense of abandonment by the physicians and the system that they had initially trusted. One family member's statement captured this common concern:

The lack of concern for the victim's and their families was far worse for all of us than [if they] had admitted [a] mistake and apologized, which never happened since they would never admit fault.

This family member was a healthcare provider whose mother died of sepsis caused by a hospital-acquired vancomycin-resistant enterococcus central-venous line infection.

Of those who pursued a legal solution only $27 \%$ (45/ $165)$ reached the settlement phase, and $17 \%(28 / 165)$ received compensation. Previous research has shown that patients would be less upset if the physician explained how the error occurred and apologised. ${ }^{31}$ This sentiment was also reflected in several open narratives that expressed a desire for recognition of fault.

There has to be a manner in how to hold doctors and medical staff accountable for their actions. I don't believe in lawsuits to correct such situations, but there is a great need for improvement.

This family member's loved one experienced a marked delay in the diagnosis of a brain tumor, an MRI identifying the tumor just prior to the patient's death.

In addition, a significant number of open narratives (34/450) expressed a desperate need for answers that never came. Patients and families who did have a provider who acknowledged fault and apologised expressed a sense of closure that other respondents did not.

She [physician] replied, "Of course it was my fault, it was entirely my fault. Who else's fault could it have been?" This made me think the world of her. I didn't take it as an apology, and I didn't think it indicated mistake or negligence. I took it as a statement that my doctor felt responsible for me.

This patient suffered perforation of her small bowel during elective upper gastrointestinal track endoscopy resulting in sepsis and necrotizing pancreatitis.

The doctor who treated me apologized and said he missed a blood clot. For that part I was grateful and told him I appreciated his follow-up and honesty and again was admitted to hospital.

This patient suffered pulmonary embolus that was missed on his first Emergency Room visit.

\section{Communication failures}

Communication failures were characterised into several subthemes, abandonment, disrespect, intimidation and failure to listen. Overall, both patients and family members expressed a lack of communication with healthcare providers. Patients, families and informal caregivers felt that they were not being heard and that their concerns were often not addressed.

I was complaining about fever and pain since I was at the hospital, and no one paid attention to my symptoms.

This patient suffered a severe postoperative infection that was not diagnosed for 5 days resulting in a large draining abdominal wall ulcer that persisted for over 2 months.

The bottom line is that I feel they wrote me off as a hysterical hypochondriac and I am quite certain that is written in his progress notes because the day I brought the little jar of yellow liquid in for my post-op appointment he wouldn't even look at me because he was so angry that I wasn't accepting that all was okay. To this day I have said to others and myself...if I can't get a surgeon to listen to ME, what does the lay-public do?

This physician underwent sinus surgery that failed to remove an obstructing lesion resulting in continued nasal drainage, and because of the first surgeon's refusal to acknowledge the problem, a second surgeon had to be recruited to perform corrective surgery.

Care providers need to listen to family members, parents and friends. We know our loved ones better than anyone else. If we tell them something isn't right they should stop and ask us questions. We see the little changes before they become apparent to others.

This parent watched her child clinically deteriorating on the hospital ward, and despite repeatedly expressing her concerns, rescue was delayed and her child died.

Some respondents suggested potential physicianlevel barriers for why concerns were not addressed during their clinical encounters.

Doctors need to stop thinking of themselves as 'know-it-alls' and listen to what the patient says... doctors need to look at patients as individuals without preconceived notions.

This patient claims to have received multiple unnecessary tests during her outpatient clinic visit, and did not receive care to relieve her symptoms.

At times when respondents attempted to convey the nature or severity of their current health status they were disregarded.

When I told her I felt my throat was closing she took the Red Robinson suctioning device, handed it to my daughter and said, 'suction your mother' and left the room.

This patient suffered a severe post-operative neck infection, and despite pus draining from her incision, operative intervention was delayed for over 8 hours. 
In some cases, patients said that they were met with hostility when they offered feedback and additional information, or asked questions:

That's when he got offended. He then slammed his computer shut and sharply yelled, 'I'm done!' I tried to reason with him and explain that I was just trying to help him. Then he yells even louder, 'I don't like people telling me how to do my job!

This patient had experienced two weeks of severe cough and a severe sore throat interfering with sleep. She was asking if she should receive antibiotics.

\section{The profound impact of the adverse events}

The self-reported, long-term effects of adverse events are summarised in figure $2 \mathrm{~B}$. Slightly over one-third reported suffering from serious postevent psychological stress, and for one-third of patients the perceived errors in care proved fatal. One-third suffered significant financial loss, and nearly one-third required follow-up surgery or therapy. Patients were also often left with chronic pain, and/or long-term or permanent loss of function. Respondents noted that family members often experienced emotional trauma (over two-thirds) (figure 2C), and approximately half reported that their family was stressed over caregiving, suffered financial loss and experienced significant loss of lifestyle. Box 1 lists quotes from respondents

Box 1 Respondent descriptions of the impact of the adverse event

\footnotetext{
"Trauma, financial loss, depression"

"Tremendous emotional stress"

"Chronic pain and total lifestyle change"

"Very troubled. I can't describe the anxiety"

"Financial, physical and emotional disaster"

"Loss of insurance"

"Horrible fear, upset, confused"

"I have been made to feel like I wasn't of concern"

"I tried my best to shield my loved ones from the trauma"

"Tragic. It tore my family completely apart"

"We will never be the same"

"She had three small children at the time of her death"

"It is difficult to capture the degree of emotional trauma"

"Great emotional toll"

"Extensive cost-loss of relationship and communicationisolation"

"The pain and agony of seeing a wife/mother unable to care for her own needs"

"It was devastating to watch him die a slow death"

"It destroyed our lives"

"Ended up my wife divorced me"

"Devastation"
}

describing the negative impact of these events. Respondents felt traumatised by providers and no longer trusted them or the health system.

I now ask for copies of all tests so that I can see the results of tests myself, and (I do) not have to trust that the doctor is telling me the truth.

This diabetic patient acquired an MRSA skin infection in the hospital and after her doctor told her the infection was cured developed severe MRSA osteomyelitis that resulted in a severe foot deformity.

I have no trust in the medical profession now. I suspect every Dr. not knowing if they are really being honest and have my best interests at heart.

This patient suffered avascular necrosis of both hips after her doctor treated her with corticosteroids for her migraine headaches (known to be ineffective therapy). ${ }^{32}$

\section{Patient suggestions for preventing adverse events}

Part of the open narrative request was to offer suggestions for how the adverse event might have been prevented. The majority of respondents made suggestions that fell into three categories: use of protocols, coordination between providers and improved listening. Respondents pointed to systems-level changes that might have prevented the adverse event, especially for those who suffered from infection.

Just maybe [infections would be reduced] if these health care professionals would not answer their cell phone while examining patients; maybe if they would change gloves consistently between patients and wash their hands completely; just maybe not wear the hospital uniforms out into the street then back into ICU or into the infectious disease unit.

Concerns of a mother who witnessed her son die of septic shock due Acinetobacter baumannii acquired soon after undergoing renal transplant surgery

Additionally, some respondents commented on the responsibility of providers to adhere to system-level measures to reduce infections.

The placement of containers for hand sanitizers, vinyl gloves, vinyl gowns, sinks, etc., are a start, but consistent and conscientious use by all staff is critical.

The recommendations of a husband whose wife was admitted with chronic venous stasis ulcers that became chronically infected with MRSA in the hospital.

Patient and families expressed concern with regards to failure of health systems to properly supervise inexperienced physicians:

No one that day had my medical history nor knew me, I was injured from neglect, inexperience and incompetency.

This patient was an R.N. who suffered a laceration of her bladder during her caesarian section performed by 
an inexperienced surgical resident who was not being supervised.

Recommendations for improvement were offered by a nurse who lost her prematurely born daughter to a fatal overdose of zinc mistakenly added to her child's hyperalimentation solution. Her comments capture the sentiments of nearly all respondents.

Initial disclosure and an apology could have given me validation and the feeling of being more empowered, but we did not receive that. We felt abandoned by the hospital, who was $100 \%$ responsible for our daughter's death. Their desire to (cover up the error) exceeded their humanity; they treated us as if we had done something wrong and as if we were an inconvenience. The re-current theme I have read through countless articles on medical mistakes and medication errors is that patients and their families often feel powerless, abandoned and deceived by the institution. Families worry that the event that injured their loved one will happen again and that their loved ones death would be in vain. I felt all of this. It was going to the news and speaking out that made me feel empowered. What I encourage healthcare facilities to do is: develop an early disclosure policy. This can take the guesswork of what to do and when to do it. Don't be reactive; be proactive with disclosure.

When patients are injured or die, family members are deeply committed to correcting the problem that led to their loved one's injury or death. They strongly support transparency and open communication as critical conditions for improving patient safety.

\section{Desire for shared decision-making}

The final major theme related to patients' requests for shared decision-making and patient empowerment, conditions that they regarded as important for reducing medical errors. Patients and families felt that their opinions and concerns were not considered:

There was no communication with the family whatsoever. We were there. We should have been included in any decisions.

This family member's father died following multiple surgical procedures to control a severe postoperative infection.

Patients felt that they should be treated as experts with regards to their own experiences, but found that this approach was a rarity:

I think I know my body a lot better than he [the doctor] does. He just didn't listen to me.

This patient was visiting her new primary care physician for the third time, and when she described her complaints during each visit, she felt he repeatedly ignored them.

Families too often commented that providers dismissed patient's and family member's concerns:

\begin{abstract}
Nonetheless, the surgeon literally waved his hand in front of us to 'shush' us, saying he had performed hundreds of bypass surgeries and there was nothing we could offer that could possibly be of use to him.
\end{abstract}

This family member was trying to warn the surgeon that her father had suffered recurrent staphylococcal infections making him a high risk for surgery. The surgeon ignored her warning, operated, and her father died of a staphylococcal (MRSA) postoperative infection.

Patients and their families wanted to partner with their providers and were asking providers to embrace a patient-centred approach to their care.

I would like staff (mainly doctors, nurses seem to be much nicer) to realize that the patient is stressed. They need information, they need choices and they need the right to control their own treatment (if they are capable) or designate someone to take care of that.

This patient came to the Emergency Room with pancreatitis. She received insufficient pain medication, her IV infiltrated, and her friend who was trying to serve as her advocate was removed from her room.

\section{DISCUSSION}

The purpose of our nationwide voluntary survey was to relay to healthcare providers and administrators a first-hand quantitative and qualitative view of the impact that adverse medical events has on patients and their families. Our patient-initiated survey confirms the quantitative findings of previous providerinitiated patient surveys suggesting that our survey is likely to be a representative sample of adverse events. In addition to categorising adverse events, we have qualitatively analysed the personal written narratives of 450 injured patients and their family members. Adverse events were often accompanied by a sense that providers and health systems did not feel responsible or accountable for the harm that patients and family experienced. Second, patients and families felt that providers failed to effectively communicate with them both before and after the adverse event, and too often when providers did communicate the interactions were disrespectful. Third, those who had suffered medical harm emphasised the profound emotional, physical and financial impact of these events. In the hopes of preventing similar adverse events from impacting future patients, they offered constructive suggestions for preventing future errors. They encouraged providers to follow infection control and other safety protocols, and to listen and respond when patients or family members express concerns about the patient's medical condition. Based on our 
respondents' narratives, such concerns should be regarded as an early warning of a potential adverse event.

As discussed in the introduction, investigators have long recognised the importance of patient surveys and recently British healthcare providers have been attempting to design a valid patient measure of safety in hospitals based on 'think out loud' interviews with patients and short surveys. The key domains they identified were communication, individual factors (eg, provider attitudes and stress), team factors and dignity and respect. ${ }^{33} 34$ It is of interest that our qualitative analysis of written narratives also identified communication, individual factors (particularly attitude), coordination of care and dignity and respect as key attributes for a safe and nurturing healthcare system environment. One condition that has not been emphasised in prior patient surveys is the importance patients attribute to shared decision-making. Our narratives reveal that patients and families would like to be part of the medical decision-making process. When a partnership exists between the provider and the patient there is greater understanding and a greater likelihood that management decisions will be tailored to the patient's needs. ${ }^{35-37}$

With regard to dignity, our open narratives revealed that a number of patients and family members regarded healthcare providers as curt and authoritarian, conditions that lead to loss of dignity. ${ }^{38}$ Another important issue that relates to dignity and respect was the perceived responses of the healthcare professionals and health system when a patient was injured by an adverse event. When patients are harmed they are asking providers to take responsibility and help them to recover rather than 'deny and defend'. ${ }^{39}$ Too often providers are constrained by the prevailing legal system and are instructed to avoid communication with injured patients. However, most patients and families do not understand these mitigating circumstances, and rightfully feel that providers and the system have abandoned them in their time of need. Our narratives reveal that patients and families view the system and the providers as one, and when the system is designed to hide fault the providers are seen as untrustworthy, fuelling the desire to take legal action. $^{31}$

Reports of provider-initiated patient surveys of medical errors suggest that patient surveys can complement health professional incident reporting and chart reviews to identify adverse events, and investigators have recommended that health systems initiate patient surveys of adverse events to more accurately estimate the incidence of medical errors. ${ }^{21-23} 40$ A concern that has recently been expressed in a review of patient reports of safety incidents is the fact that all studies to date have been clinician-led. Furthermore, these studies have actively 'solicited' reports from patients, by interview or written survey. None of the study designs to date have allowed patients to spontaneously report patient safety incidents. Finally, the study designs of previously published patient reports are likely to have missed insights from the families of patients who suffered fatal outcomes, thus underestimating the severity of the problem. ${ }^{40}$

We recommend an alternative approach. Why not encourage patients and patient advocates to administer their own surveys as we have done? Patient organisations could be created to initiate surveys both locally and nationally, and the results could serve as the basis for forums where patient suggestions for improvement could be generated. This strategy promises to increase patient belief that preventive measures can be effective, ${ }^{41}$ and will increase the voice of the patient in our healthcare systems.

\section{LIMITATIONS}

Voluntary patient surveys are inherently biased because respondents represent a self-selected population and their descriptions are self-reported. These narratives and our qualitative analysis represent the patients' and families' perceptions, and given the complexity of care, it is not possible to prove whether or not medical harm was directly attributable to medical errors. Furthermore, we recognise that the many, or even most, providers communicate effectively and empathetically with their patients. Nonetheless these results represent a robust patient-initiated survey that documents the experiences and perceptions of the recipients of medical care, and can provide helpful feedback for providers and healthcare systems.

\section{CONCLUSIONS}

Our nationwide patient-initiated voluntary survey consisting of 696 respondents confirms previously published provider-initiated patient surveys with regard to the relative frequency of different categories of medical and surgical errors. Qualitative analysis of 450 written narratives highlights the concerns of patients and families who have experienced adverse events. They perceived a lack of accountability on the part of both caregivers and health systems, and repeatedly commented on poor and at times disrespectful communication both before and after the adverse event. Many described profound suffering, and as a consequence of how they were treated, a loss of trust in their health delivery system and providers. Respondents made a number of suggestions for improvement, and emphasised the importance of patients and families being actively involved in decisions about their care. When working to improve the quality and safety of patient care, patients and providers share common goals. And we recommend that patients be encouraged to become part of the solution by creating local surveys similar to our national survey with the goal of providing meaningful feedback to their community's providers and healthcare delivery systems. 
Twitter Follow Frederick Southwick at @FS_Southwick

Acknowledgements We would like to thank the many patients and families who devoted their time to fill out our survey. This qualitative analysis is based on data collected from the survey developed by Helen Haskell and Julia Hallisy of the Empowered Patient Coalition. We acknowledge the support of the Consumers Union Safe Patient Project in the launch of the survey and in the initial public outreach efforts. We thank Mary Ellen Young, PhD, Department of Behavioral Science and Community Health, University of Florida, as well Martha Bojko, PhD and Julia Rosanova, PhD both from the Department of Psychiatry, Yale College of Medicine, for assistance with our qualitative analysis, and Frank Davidoff, MD, Steven Southwick, MD, and John James, for their editorial assistance. This project was approved as exempt by the University of Florida IRB-01, approval number IRB201300839.

Contributors FSS: wrote the manuscript and reviewed the applicable literature, and also assisted in analysing the data. NMC: performed the qualitative analysis of the open narratives using NVivo software under the supervision of Fred Southwick. JAH: designed and administered the survey and collated the survey responses. She also reviewed the manuscript and made suggestions for improvement.

Competing interests None declared.

Ethics approval Institutional review board.

Provenance and peer review Not commissioned; externally peer reviewed.

Data sharing statement The survey is ongoing, and following publication all data in the paper and all subsequent survey results will be shared online through the website http:/ empoweredpatientcoalition.org/

Open Access This is an Open Access article distributed in accordance with the Creative Commons Attribution Non Commercial (CC BY-NC 4.0) license, which permits others to distribute, remix, adapt, build upon this work noncommercially, and license their derivative works on different terms, provided the original work is properly cited and the use is non-commercial. See: http://creativecommons.org/licenses/by$\mathrm{nc} / 4.0 /$

\section{REFERENCES}

1 Kohn LT, Corrigan J, Donaldson MS, et al. To err is human: building a safer health system. Washington DC: National Academy Press, 2000.

2 Southwick FS. Recovering from a medical error. http:// recoveringfromamedicalerror.org/ (accessed 23 Feb 2015).

3 Consumer's, Union. Safe patient project. http:// safepatientproject.org/ (accessed 10 Jun 2015).

4 Skolnik P. Citizens for patient safety. http://www. citizensforpatientsafety.org/ (accessed 23 Feb 2015).

5 Corina I. Pulse of New York. http://pulseofny.org/ (accessed 23 Feb 2015).

6 Kenney L. Medically induced trauma support services. http:// www.mitss.org (accessed 23 Feb 2015).

7 Leah's Legacy. http://www.leahs-legacy.org/ (accessed 23 Feb 2015).

8 The Niles Project. http://www.nilesproject.com (accessed 23 Feb 2015).

9 Patient Safety ASAP. http://patientsafetyasap.org/ (accessed 23 Feb 2015).

10 The Peggy Foundation. http://peggyfoundation.org/ (accessed 23 Feb 2015).

11 Hallisy JA. The empowered patient. San Francisco, CA: Bold Spirit Press, 2008.

12 McIver S, Wyndham R. After the error. Toronto, Ontario, Canada: ECW Press, 2013.
13 Gibson R, Singh JP. Wall of silence: the untold story of the medical mistakes that kill and injure millions of Americans. Washington DC: Lifeline Press, 2003.

14 Gilbert SM. Wrongful death. New York, NY: W.W. Norton \& Company Inc, 1997.

15 King S. Josie's story. New York, NY: Atlantic Monthly Press, 2009.

16 Mastors P. Designed to survive: 9 ways an IKEA approach can fix health care and save lives. New York, NY: Morgan James Publishing, 2013.

17 James JT. A sea of broken hearts: patient rights in a dangerous, profit-driven health care system. Bloomington, IN: AuthorHouse, 2007.

18 Torrey T. You bet your life! The 10 mistakes every patient makes-how to fix them to get the healthcare you deserve. Minneapolis, MN: Langdon Street Press, 2010.

19 Millenson ML. Demanding medical excellence: doctors and accountability in the information age. Chicago, IL: University of Chicago Press, 2000.

20 Southwick FS. Critically ill: a 5-point plan to cure healthcare delivery. Gainesville, FL: Southwick Press, 2014.

21 Weissman JS, Schneider EC, Weingart SN, et al. Comparing patient-reported hospital adverse events with medical record review: do patients know something that hospitals do not? Ann Intern Med 2008;149:100-8.

22 Weingart SN, Pagovich O, Sands DZ, et al. What can hospitalized patients tell us about adverse events? Learning from patient-reported incidents. J Gen Intern Med 2005;20:830-6.

23 Zhu J, Stuver SO, Epstein AM, et al. Can we rely on patients' reports of adverse events? Med Care 2011;49:948-55.

24 Southwick FS. Opinion/editorial: losing my leg to a medical error. New York Times, February 2013.

25 Southwick F. Who was caring for Mary? Ann Intern Med 1993;118:146-8.

26 Hallisy J. The empowered patient coalition. http:// empoweredpatientcoalition.org/ (accessed 16 Mar 2015).

27 Department of Health and Human Services, Office of Inspector General. Adverse events in hospitals: national incidence among medicare beneficiaries. http://oig.hhs.gov/oei/ reports/OEI-06-09-00090.pdf (accessed 16 Mar 2015).

28 Strauss AL. Qualitative analysis for social scientists. New York, NY: Cambridge University Press, 1987.

29 Giles EL, Sniehotta FF, McColl E, et al. Acceptability of financial incentives and penalties for encouraging uptake of healthy behaviours: focus groups. BMC Public Health 2015;15:58.

30 Strauss A, Corbin JM. Basics of qualitative research: techniques and procedures for developing grounded theory. 2nd edn. Thousand Oaks, CA: Sage Publications Inc, 1998.

31 Gallagher TH, Garbutt JM, Waterman AD, et al. Choosing your words carefully: how physicians would disclose harmful medical errors to patients. Arch Intern Med 2006;166:1585-93.

32 Fiesseler FW, Shih R, Szucs P, et al. Steroids for migraine headaches: a randomized double-blind, two-armed, placebo-controlled trial. J Emerg Med 2011;40:463-8.

33 Giles SJ, Lawton RJ, Din I, et al. Developing a patient measure of safety (PMOS). BMJ Qual Saf 2013;22:554-62.

34 McEachan RR, Lawton RJ, O'Hara JK, et al. Developing a reliable and valid patient measure of safety in hospitals (PMOS): a validation study. BMJ Qual Saf 2014;23:565-73. 
35 Mitnick S, Leffler C, Hood VL, et al. Family caregivers, patients and physicians: ethical guidance to optimize relationships. J Gen Intern Med 2010;25:255-60.

36 Yin HS, Dreyer BP, Vivar KL, et al. Perceived barriers to care and attitudes towards shared decision-making among low socioeconomic status parents: role of health literacy. Acad Pediatr 2012;12:117-24.

37 Street RL Jr, Richardson MN, Cox V, et al. (Mis)understanding in patient-health care provider communication about total knee replacement. Arthritis Rheum 2009;61:100-7.
38 Baillie L. Patient dignity in an acute hospital setting: a case study. Int J Nurs Stud 2009;46:23-36.

39 Kachalia A, Kaufman SR, Boothman R, et al. Liability claims and costs before and after implementation of a medical error disclosure program. Ann Intern Med 2010;153:213-21.

40 Ward JK, Armitage G. Can patients report patient safety incidents in a hospital setting? A systematic review. BMJ Qual Saf 2012;21:685-99.

41 Schwappach DL. Review: engaging patients as vigilant partners in safety: a systematic review. Med Care Res Rev 2010;67:119-48. 